\title{
Coexistence of Virulence and Antibiotic Resistance Genes in Pasteurella multocida Isolated
} from Diseased Rabbits

\author{
Naglaa, F.S. Awad ${ }^{1}$ and Marwa, I. Abd El-Hamid ${ }^{* 2}$ \\ ${ }^{1}$ Department of Avian and Rabbit Medicine, Faculty of Veterinary Medicine, Zagazig \\ University, Zagazig, Sharkia, 44519, Egypt \\ ${ }^{2}$ Department of Microbiology, Faculty of Veterinary Medicine, Zagazig University, Zagazig, \\ Sharkia, 44519, Egypt
}

Article History: Received: 3/12/2018 Received in revised form: 8/1/2019 Accepted: 25/1/2019

\begin{abstract}
Pasteurella multocida (P. multocida) is considered a predominant pathogenic bacterial agent causing respiratory manifestations (snuffles) in rabbits with considerable economic losses and unfavorable prognosis in Egypt. A few recent $P$. multocida strains exhibit resistance to the most commonly used antibiotics in the veterinary field. Therefore, the present study was carried out to investigate the prevalence of both virulence and antibiotic resistance genes among $P$. multocida isolated from diseased rabbits in Sharkia Governorate, Egypt. Only 10 out of 100 tested rabbits` nasal swabs were finally confirmed positive for $P$. multocida of serogroup A by polymerase chain reaction (PCR). Antibiotic susceptibility testing of the recovered isolates revealed that they were all multidrug resistant (MDR) with a predominance of resistance to amoxicillin, ampicillin, amoxicillin/clavulanic acid, neomycin and tetracycline (100\% each), followed by kanamycin and streptomycin (90\% each). All the recovered isolates were further subjected to PCR screening of some common virulence and antibiotic resistance genes of interest . With the exception of toxA gene, the other virulence associated genes ( $p t f \mathrm{~A}, O \operatorname{mp} 87$ and $n a n \mathrm{~B}$ ) were found among all the examined isolates. Totally, all MDR P. multocida isolates contained at least one antibiotic resistance gene with aphA1 being the most prevalent (100\%), followed by ermX gene (40\%). Antibiotic resistance genotyping demonstrated the presence of multiple antibiotic resistance genes among majority of the isolates (40\%) with only one isolate harboring 4 genes encoding identical resistance phenotypes. Evidentially, all MDR $P$. multocida isolates possessed at least 3 virulence genes accompanied by the attendance of antibiotic resistance genes. These findings evidenced that rabbits are potential sources of pathogenic $P$. multocida strains harboring virulence and antibiotic resistance genes. Therefore, it is evident that there is an urgent need for the judicious use of antibiotics in rabbits' treatment systems to successfully mitigate the propagation of drug resistance across $P$. multocida species.
\end{abstract}

Keywords: $P$. multocida, Rabbits, Multi-drug resistant, Antibiotic Resistance Genes, Virulence Factors.

\section{Introduction}

Rabbit pasteurellosis is a highly contagious disease of domestic rabbits caused by Pasteurella multocida (P. multocida) [1]. The disease is characterized by various clinical manifestations including rhinitis (snuffles) with purulent nasal discharge, abscesses, otitis media, pneumonia, pyometra, orchitis and septicemia [2,3]. The stress and immunodeficiency of hosts play a major role in the development of pasteurellosis by autoinfections [4].
P. multocida is a Gram negative commensal pathogen in a wide host range including mammals, birds and humans [5]. Serologically, it is classified into five capsular serogroups (A, B, D, E and F) and 16 lipopolysaccharide (LPS) somatic serotypes (1-16) [6]. Pasteurellosis in rabbits is mainly caused by the capsular type A and to a lesser extent type D P. multocida strains [7]. Capsular type $F$ strains have been also recorded in rabbits [8].

\footnotetext{
*Corresponding author e-mail: (mero_micro2006@yahoo.com), Department of Microbiology, Faculty of Veterinary Medicine, Zagazig University, Egypt, 19thSaleh Abo Rahil Street, El-Nahal, 44519, Zagazig, Sharkia, Egypt
} 
The polysaccharide capsule and LPS are of the major important virulence determinants contributed in the pathogenesis of $P$. multocida [9]. However, many other putative virulence factors are related to pathogenicity including adherence and colonization factors, fimbriae, iron regulating and acquisition proteins, exotoxins and extracellular enzymes [10].

Using the antimicrobial therapy for controlling rabbit pasteurellosis is failing to bring an end to many infections due to the emergence of multi-drug resistant (MDR) strains with a great potential for transfer of this resistance from animals to human. As a result, the antibiotic resistance phenomenon among pathogenic bacteria has become a growing problem in veterinary and human medicininal fields [11]. This leads to increased treatment costs, prolonged illness and sometimes death with adverse effects on the economy of Egypt [12]. Therefore, pre-testing of antibiotics susceptibility is essential to select the effective drugs to be used by the veterinarians in the field [13].

Data on the antibiotic resistance and virulence properties of individual $P$. multocida strains would help to implement appropriate preventive strategies. Assessing the distribution of resistance genes represents a more detailed and potentially beneficial additional tool for better understanding antimicrobial resistance, particularly in Egypt, where existing data is quite limited. Additionally, the description of co-occurrence between virulence and resistance in $P$. multocida from rabbits has not been reported in Egypt. These knowledge gaps encourage the need for researches in theses serious issues.

Therefore, the present investigation aimed to assess the occurrence of $P$. multocida in rabbit farms from different localities at Sharkia Governorate as well as their possession of four important virulence-associated genes ( $p t f \mathrm{~A}$, Omp87, nanB and toxA) putatively involved in the pathogenesis of $P$. multocida. Moreover, we documented the phenotypic and genotypic characteristics of antibiotic resistance among the recovered $P$. multocida isolates to clarify the relationship between the phenotypic and genotypic resistance profiles. Finally, we attempted to associate the co-presence of virulence and antibiotic resistance which is becoming more profitable for the pathogenic bacteria.

\section{Materials and Methods \\ Clinical data and specimens collection}

The study was approved by the Committee of Animal Welfare and Research Ethics, Faculty of Veterinary Medicine, Zagazig University. It was performed on a total of 100 clinically diseased rabbits originated from five rabbitries in different localities at Sharkia Governorate. They were admitted to the clinic of Avian and Rabbit Medicine Department, Faculty of Veterinary Medicine, Zagazig University with respiratory manifestations (oculonasal discharge, sneezing and coughing) during the period from March 2017 to August 2018. Owing to the major role of stress in the development of pasteurellosis in rabbits, relevant information was obtained from the owners of the diseased rabbits before bacteriological examination. The five investigated rabbitries revealed the following stress factors; improper rabbit hutch (a small or a glass cage), poor quality of feeding as carrots, overcrowding, improper or excessive handling, transportation, poor ventilation, extreme temperature, pregnancy, parturition, heavy lactation and bad management (excessive ammonia level). The external nares of the diseased rabbits were swabbed using sterile cotton-tipped swabs.

\section{Isolation and identification of Pasteurella multocida}

$P$. multocida was isolated and identified according to the conventional protocols stated previously [14]. Briefly, each swab was inoculated into brain heart infusion (BHI) broth (Oxoid, Hampshire, UK) and incubated aerobically at $37^{\circ} \mathrm{C}$ for $24 \mathrm{~h}$. Subsequently, a loopfull from the enriched broth was streaked on each of blood agar media supplemented with 5\% fresh sheep blood and MacConkey`s agar plates (Oxoid, Hampshire, UK). After overnight incubation at $37^{\circ} \mathrm{C}$ under aerobic conditions, all the isolates that did not grow on MacConkey`s agar and showed typical colonies of Pasteurella spp. on blood agar were further confirmed using a series of 
biochemical tests including oxidase, catalase, indole and urease production according to the standard laboratory procedures [15]. Presumptive isolates were confirmed as $P$. multocida by PCR amplification of the species specific kmt1 gene fragment [16]. The capsular types of the confirmed $P$. multocida isolates were then determined using the multiplex PCR assay [17].

\section{Antibiotic susceptibility testing}

All the recovered $P$. multocida isolates were examined for their antibiotic susceptibility patterns against 10 antibiotic agents of four different groups by the KirbyBauer disk diffusion method [18]. Overnightgrown cultures were spread onto Mueller Hinton agar plates to form a bacterial lawn; thereafter, antibiotic discs (Oxoid, Hampshire, $\mathrm{UK}$ ) were evenly placed and then the plates were incubated at $37^{\circ} \mathrm{C}$ for $24 \mathrm{~h}$.

The tested antibiotic agents were commonly used in poultry industry including ampicillin (AM, $10 \mu \mathrm{g})$, amoxicillin (AX, $25 \mu \mathrm{g}$ ), amoxicillin/clavulanic acid (AMC, 20/10 $\mu \mathrm{g}$ ), neomycin $(\mathrm{N}, 30 \mu \mathrm{g})$, gentamicin $(\mathrm{CN}, 10 \mu \mathrm{g})$, kanamycin $(\mathrm{K}, 30 \mu \mathrm{g})$, streptomycin $(\mathrm{S}, 10$ $\mu \mathrm{g})$, erythromycin (E, $15 \mu \mathrm{g})$, tetracycline (TE, $30 \mu \mathrm{g})$ and doxycycline (DO, $30 \mu \mathrm{g})$. The inhibition zones' diameters were measured and scored as sensitive (S), intermediate (I) and resistant (R) according to the European Committee on Antimicrobial Susceptibility Testing (EUCAST) clinical breakpoint table version 7.12017 [19]. Isolates showing resistance to at least 3 different antibiotic groups were categorized as MDR.

\section{Molecular detection of virulence and resistance associated genes}

The presence of four virulence genes encoding adhesins ( $p t f \mathrm{~A})$, protectins (Omp87), sialidases (nan $\mathrm{B})$ and dermonecrotoxin $(\operatorname{tox} \mathrm{A})$ were examined in all recovered $P$. multocida isolates by individual PCR protocols utilizing specific oligonucleotide primers [20,21].

For detecting the corresponding antibiotic resistance genes in all phenotypic resistant isolates, target genes conferring resistance to $\beta$-lactams (blaROB-1), aminoglycosides (aphA1), macrolide (ermX) and tetracyclines $($ tet $\mathrm{H})$ were screened by PCR assay. The primer sequences and cycling conditions were as described previously [22]. All runs were repeated 3 times in parallel with the relevant positive and negative controls. The details of the oligonucleotide primers used to detect virulence and resistance genes are depicted in Table 1. 
Table 1: Primers used for the detection of $P$. multocida serogroups and their virulence and resistanceassociated genes

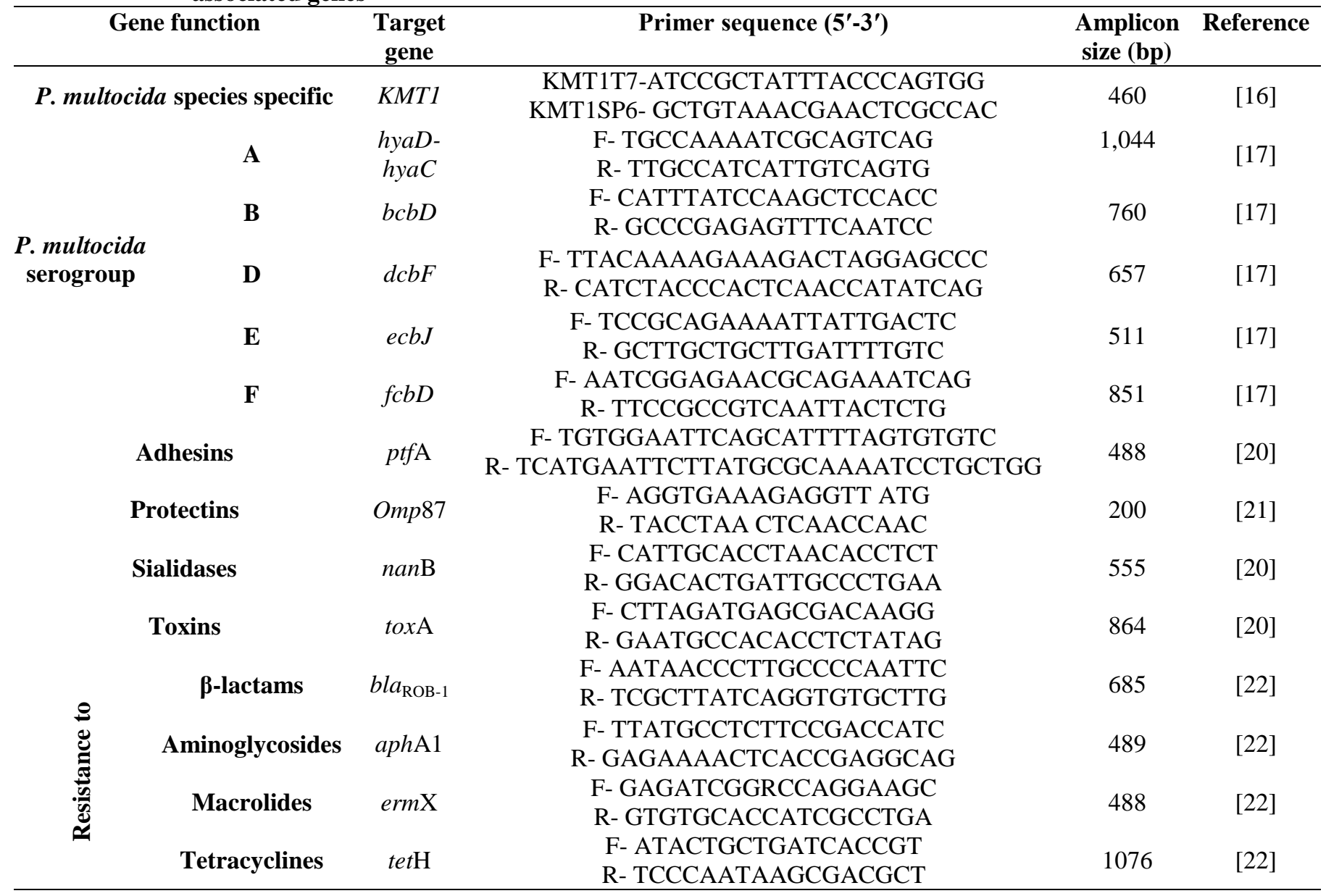

\section{Results \\ Frequency and identification of $P$. multocida among diseased rabbits}

Ten out of 100 rabbits (10\%) examined in this study were positive for $P$. multocida. On blood agar medium, the colonies were smooth, glistening, iridescent, dew drop, convex and non-haemolytic; meanwhile, there was no growth on MacConkey's agar plates. Microscopic examination of the colonies revealed that they were Gram-negative, nonmotile, non-spore forming and coccobacilli shaped bacteria. The 10 isolates produced positive reactions with indole, oxidase and catalase tests, while they were negative for urease utilization test. The above examined criteria identified those isolates as Pasteurella spp. All the isolates were confirmed as $P$. multocida based on the PCR amplifications of $k m t 1$ species specific gene fragments. All the isolates were of serogroup A as was identified by multiplex PCR for the detection of their capsular types.

\section{Antibiotic sensitivity test}

The distribution of antibiotic resistance among the analyzed isolates is presented in Figure 1A. All the isolates exhibited full resistance to ampicillin, amoxicillin, amoxicillin/clavulanic acid, neomycin and tetracycline $(100 \%)$, followed by kanamycin and streptomycin (90\%, each) and erythromycin and doxycycline (80\% each). Resistance to at least 7 antibiotic agents was detected in $P$. multocida isolates with a remarkable MDR pattern being observed across all the tested isolates. Interestingly, four isolates $(40 \%)$ were resistant to all tested antibiotics (Table 2). 
Table 2. Phenotypic antibiotic resistance and presence of virulence and antibiotic resistance genes among ten $P$. multocida isolates of naturally infected rabbits

\begin{tabular}{lccc}
\hline $\begin{array}{l}\text { Isolate } \\
\text { code } \\
\text { No. }\end{array}$ & Phenotypic antibiotic resistance profile & Antibiotic resistance gene(s) & Virulence genes \\
\hline 1 & AM, AX, AMC, CN, N, S, K, E, TE & aphA1 & ptfA, Omp87, nanB \\
2 & AM, AX, AMC, CN, N, S, K, E, TE & aphA1 & ptfA, Omp87, nanB \\
3 & AM, AX, AMC, CN, N, S, K, E, TE, DO & aphA1,ermX & ptfA, Omp87, nanB \\
4 & AM, AX, AMC, CN, N, S, K, E, TE, DO & aphA1, ermX, blaROB-1, tetH & ptfA, Omp87, nanB \\
5 & AM, AX, AMC, CN, N, S, K, E, TE, DO & aphA1 & ptfA, Omp87, nanB, toxA \\
6 & AM, AX, AMC, N, S, E, TE, DO & aphA1 & ptfA, Omp87, nanB \\
7 & $\mathrm{AM}, \mathrm{AX}, \mathrm{AMC}, \mathrm{N}, \mathrm{S}, \mathrm{K}, \mathrm{E}, \mathrm{TE}, \mathrm{DO}$ & aphA1 & ptfA, Omp87, nanB, toxA \\
8 & $\mathrm{AM}, \mathrm{AX}, \mathrm{AMC}, \mathrm{CN}, \mathrm{N}, \mathrm{S}, \mathrm{K}, \mathrm{TE}, \mathrm{DO}$ & aphA1, ermX, blaROB-1 & ptfA, Omp87, nanB \\
9 & $\mathrm{AM}, \mathrm{AX}, \mathrm{AMC}, \mathrm{CN}, \mathrm{N}, \mathrm{S}, \mathrm{K}, \mathrm{E}, \mathrm{TE}, \mathrm{DO}$ & aphA1, ermX & ptfA, Omp87, nanB, toxA \\
10 & $\mathrm{AM}, \mathrm{AX}, \mathrm{AMC}, \mathrm{N}, \mathrm{K}, \mathrm{TE}, \mathrm{DO}$ & aphA1 & ptfA, Omp87, nanB, toxA \\
\hline
\end{tabular}

AM: ampicillin, AX: amoxicillin, AMC: amoxicillin/clavulanic acid, CN: gentamicin, N: neomycin, K: kanamycin, S: streptomycin, E: erythromycin, TE: tetracycline, Do: doxycycline

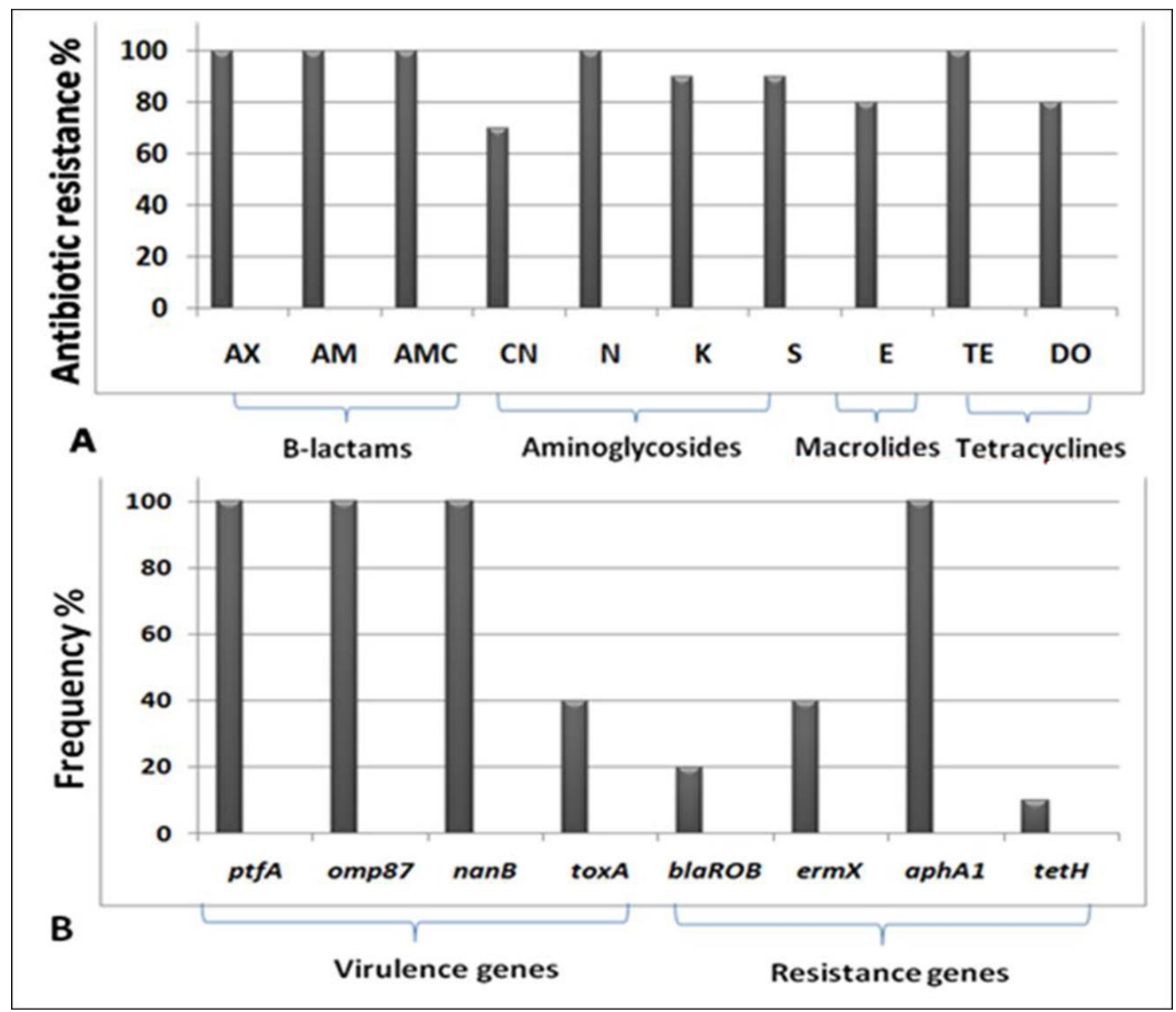

Figure 1: Frequency of antibiotic resistance (A) and virulence and antibiotic resistance genes (B) among $P$. multocida isolates from diseased rabbits. AM: ampicillin, AX: amoxicillin, AMC: amoxicillin/clavulanic acid, CN: gentamicin, N: neomycin, K: kanamycin, S: streptomycin, E: erythromycin, TE: tetracycline, Do: doxycycline. 
Virulence and resistance gene profiles of $P$. multocida isolates

The results confirmed that, with the exception of toxA gene, the other virulence associated genes were found among all examined field isolates (Figure 1B). According to the virulence genes analysis, four screened isolates harbored all examined genes ( $p t f \mathrm{~A}$, Omp87, nanB and toxA) (Table 2); meanwhile, the remaining 6 isolates possessed only 3 of these virulence associated genes (ptfA, Omp87 and nanB).

The PCR results indicated that all $10 P$. multocida isolates contained antibiotic resistance genes regardless of their susceptibility patterns using disc diffusion assay. The resistance genes commonly detected were those encoding resistance to aminoglycosides (aphA1, 100\%), followed by macrolides $(\mathrm{ermX}, 40 \%)$. The other genes conferring resistance to $\beta$-lactams and tetracyclines were present to lesser extents including blaROB-1 (20\%) and tet $\mathrm{H}(10 \%)$, respectively (Figure 1B). Except aphA1 gene which was detected in all the 10 aminoglycosides resistant isolates, the PCR detections of antibiotic resistance genes were partially consistent with the phenotypic antibiotic susceptibility criteria because majority of the genes were not detected in isolates those had the potential to confer the relevant phenotypic resistance. Notably, 4 MDR isolates $(40 \%)$ carried multiple genes with only one isolate harboring 4 genes encoding identical resistance phenotypes (Table 2). All MDR P. multocida isolates possessed at least 3 virulence genes accompanied by the existence of antibiotic resistance genes (Table 2). The expected PCR products for the examined virulence and resistance genes and their lengths are shown in Figure 2A-H.
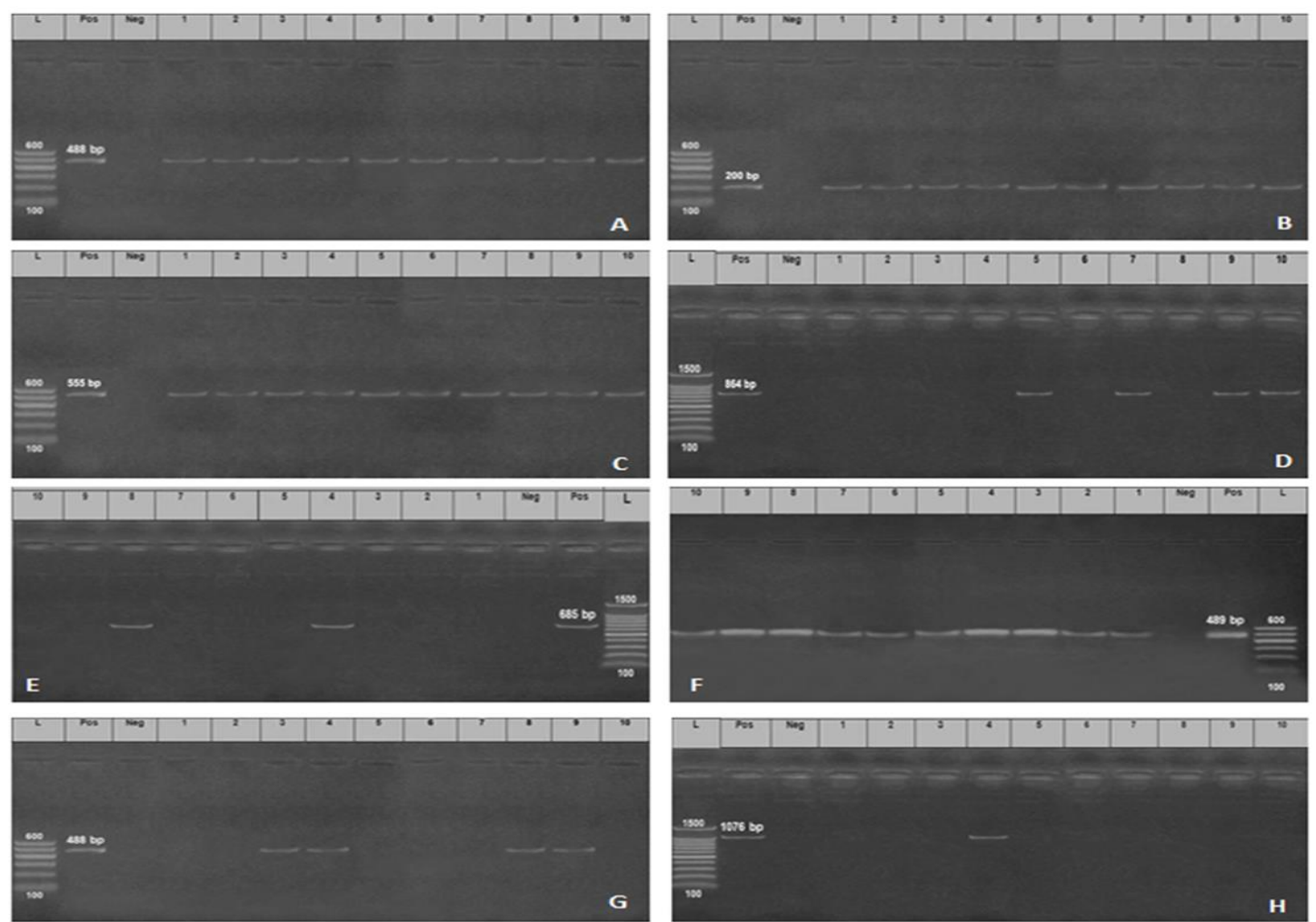

Figure 2: Agarose gel electrophoresis showing typical amplification products for virulence genes of $P$. mulocida isolated from rabbits; ptfA (A), Omp87 (B), nanB (C) and tox A (D) and antibiotic resistance genes; blaROB-1 (E), aphA1 (F), ermX (G) and tetH (H). Lane L: DNA molecular size marker (100-bp), lanes 1-10: $P$. multocida isolates from diseased rabbits, lane Pos.: positive control, lane Neg.: negative control. PCR amplification products and their sizes in base pairs (bp) are indicated. 


\section{Discussion}

Rabbit pasteurellosis continues to be a great threat facing rabbit industry in Egypt with a possibility of fatal consequences. In the current study, we demonstrated the occurrence of $P$. multocida in clinically diseased rabbits which originated from different localities at Sharkia Governorate, Egypt. Additionally, we demonstrated the distribution of MDR $P$. multocida isolates as well as their virulence and resistance genes' profiles. We then monitored the co-occurrence of both virulence and resistance genes among the analyzed isolates. Ten $P$. multocida isolates were isolated from 100 nasal swabs collected from diseased rabbits with respiratory manifestations (10\%). This result was nearly similar to those obtained by previous reports in Kafr El Sheikh (9.4\%) [23] and Brazil (7.4$10 \%$ ) [12]. On the other hand, the isolation percentage of $P$. multocida in the current study was low when compared with other previous reports in different Governorates in Egypt; Sharkia (47.5\%) [24] and Kaliobeya (27\%) [25]. The variation in the frequencies of $P$. multocida may be attributed to differences in geographical distributions, environmental conditions, stress factors, health and immune status of each examined rabbit and genetic resistance.

The recovered isolates were subjected to phenotypic identification depending on standard microbiological techniques as those from previous scientific literatures [26,27]. All the recovered isolates were confirmed as $P$. multocida by PCR amplifications of 460-bp products of $k m t 1$ gene confirming that PCR is very important for rapid and specific characterization of $P$. multocida as was obtained previously [16]. Capsular typing using the multiplex PCR technique revealed that all P. multocida isolates $(100 \%)$ were of capsuler type A yielding the expected amplicons of $1044 \mathrm{bp}$. This finding is in agreement with other researches, where $P$. multocida capsuler type A were most commonly isolated from rabbits [28,29].

The antimicrobial susceptibility data from the current study indicated higher resistance rates to ampicillin, amoxicillin, neomycin and tetracycline $(100 \%)$ reported in previous studies conducted in India [30], where all $P$. multocida isolates of rabbits suffering from pasteurellosis were resistant to neomycin, penicillin and ampicillin and in Egypt [31], where all $P$. multocida isolated from diseased rabbits were resistant to tetracycline (100\% each). These findings are probably considered as a consequence of the extensive use of these antibiotics in rabbit farms. On the other hand, the data on the antibiotic susceptibility of rabbit $P$. multocida isolates available in another literature conducted in Italy showed a relatively low frequency of resistance against ampicillin and tetracycline [32]. Different geographic locations with their particular isolated strains might have caused these variations.

Concerning the resistance profiles in our study, MDR phenomenon was observed among all the recovered isolates. This observation comes in parallel with a recent report conducted in Egypt [31], where all the examined rabbit $P$. multocida strains demonstrated remarkably MDR patterns. The presence of multiresistant $P$. multocida isolates recovered from rabbits affected by pasteurellosis has already been reported in Italy [32]. In another study in Brazil, 47.8\% (22/46) of rabbit $P$. multocida strains were resistant to at least one of the tested drugs [12]. The antibiotic resistance is a growing problem probably attributed to the extensive and indiscriminate usage of antibiotics for prevention and treatment of pasteurellosis in the field.

In this study, $P$. multocida isolates were screened for the existence of four critical virulence associated genes ( $p t f A, O m p 87$, $n a n \mathrm{~B}$ and tox $\mathrm{A}$ ) involved in bacterial pathogenesis. The results confirmed that, with the exception of tox $\mathrm{A}$ gene, the other virulence associated genes were found among all the isolates. Other researches worldwide confirmed our findings and reported the occurrence of selected virulence genes encoding dermonecrotoxin production (toxA), fimbriae adhesions ( $p t f A)$ extracellular enzymes $(n a n \mathrm{~B})$ and outer membrane protein synthesis (Omp87) in P. multocida isolated from rabbits $[12,33]$. 
The high prevalence rate of $p t f A$ gene detected in this study (100\%) was expected due to it is assumed to be a key factor in fixing the bacteria on the epithelial cells' surfaces. This result agrees with the finding of other researches [12]. Moreover, nanB gene was found in all the examined isolates as was previously evidenced [33]. This could be attributed to the fact that sialidases (nan B) play an important role in colonization to epithelial surfaces of the host and they also promote the virulence of bacteria by unmasking the key receptors and reducing mucin effectiveness. With respect to toxA gene, only four isolates harbored this gene. This may be attributed to the fact that the gene which encodes dermonecrotoxin is initially detected in serotype D isolates and it was found to be associated with atrophic rhinitis in pigs [34]. Later on, it was detected in serotype A strains from pigs and other hosts [35]. Moreover, even in toxigenic isolates of pigs, the presence of this gene evidenced to be low and it is usually missing after few subcultures

Monitoring the antibiotic resistance trends among bacterial pathogens isolated from humans and animals is necessary to inform the public policy regarding the appropriate use of the antibiotics in both human and veterinary medicine [36]. To our knowledge, there were no published data regarding the prevalence of antibiotic resistance genes among $P$. multocida rabbit isolates. The current study appeared also to be the first to report the relationship between the phenotypic and genotypic resistance profiles of the recovered isolates.

The aphA1, ermX, blaROB-1 and tet $\mathrm{H}$ genes are among the aminoglycoside, macrolides, $\beta$-lactams and tetracyclines resistance determinants, respectively. They have been commonly observed in some bacterial pathogens, but data about these genes prevalence in $P$. multocida of rabbits are limited, particularly in Egypt.. The current study demonstrated a high prevalence of positive aphA1 P. multocida isolates (100\%). This gene was also detected in all $23 P$. multocida isolates from bovine respiratory infections in a previous study conducted in China [37]. Another recent Canadian study has also detected this gene in most Mannheimia haemolytica isolated from nasal swabs of cattle [22]. In the current study, genes encoding resistance to $\beta$-lactams (blaROB-1) and tetracycline $($ tet $\mathrm{H})$ showed frequencies $(20$ and $10 \%$, respectively) lower than those reported in studies carried out in Spain [38], where all $13 \quad P$. multocida isolates from diseased pigs carried blaROB-1 and in the United States and Canada [39], where 25 out of 31 pasteurella isolates from cattle, turkey and pigs $(80.64 \%)$ were found to contain tet $(\mathrm{H})$ gene.

Notably, most of the screened genes were not observed in the phenotypic resistant isolates except aphA1 gene which was detected in all of the 10 aminoglycosides resistant isolates. These results denote that there may be other antibiotic resistance genes encoding resistance that were not examined in the current study.

Finally, this study demonstrated the cooccurrence of virulence and antibiotic resistance genes among the analyzed isolates. The co-occurrence of these concerning trends confirmed that acquisition of antibiotic resistance has been accompanied by increased virulence. These findings were discussed in several reports [40,41], where the increased bacterial resistance is accompanied by an increased in their virulence. Fundamentally, the bacterial virulence is directly correlated with the evolution of antibiotic resistance from the theoretical point of view that just when the host manifests the disease clinical signs. This means that when the virulent bacterial pathogens are present, antibiotic treatment is administrated; however, in the absence of bacterial infection, exposure to antibiotics is much lower, so the possibility of emerging antibiotic resistance due to the lack of antibiotic pressure is becoming also lower.

\section{Conclusion}

Based on the previous findings, the current investigation demonstrated the high incidence of MDR and virulent $P$. multocida isolates among the clinically diseased rabbits. Our observations highlight the role of rabbits as potential sources of $P$. multocida with a wide range of virulence determinants and antibiotic resistance genes with subsequent major negative public health implications. These results should be used to emphasize the 
responsibility of the veterinarians and relevant authorities to develop prudent use guidelines to minimize the emergence and spread of MDR bacterial strains originating from rabbits in Egypt.

\section{Conflict of Interest}

None of the authors have any conflict of interest to declare.

\section{References}

[1] El Tayeb, A.B.; Morishita, T.Y. and Angrick, E.J. (2004): Evaluation of Pasteurella multocida isolated from rabbits by capsular typing, somatic serotyping and restriction endonuclease analysis. J Vet Diagn Invest, 16 (2): 121-125.

[2] Premalatha, N.; Kumar, K. S.; Purushothaman, V.; Ravikumar, G. and Manohar, B. M. (2009): Incidence of pasteureloosis (Snuffles) in a rabbit farm. Tamil Nadu J Vet Anim Sci, 5 (6): 269271.

[3] Lennox, A.M. (2012): Chapter 16respiratory disease and pasteurellosis. In: Quesenberry, K.E.; Carpenter, J.W. (Eds.), Ferrets, Rabbits, and Rodents, third edition. W.B. Saunders, Saint Louis. pp. 205-216.

[4] Quesenberry, K. E., and Carpenter, J. W. (2004). Ferrets, rabbits, and rodents: clinical medicine and surgery. $2^{\text {nd }}$ edition, Saunders, St. Louis, MO.

[5] Quinn, P.J.; Carter, M.E.; Markey, B. and Carter, G.R. (1994): Pasteurella species. In: Clinical Veterinary Microbiology. $1^{\text {st }}$ edtion. Wolfe Publishing, Mosby -Year Book Europe Limited, London. pp. 254258.

[6] Arumugam, N.D.; Ajam, N.; Blackall, P.J.; Asiah, N.M.; Ramlan, M.; Maria, J.; Yuslan, S. and Thong, K.L.( 2011): Capsular serotyping of Pasteurella multocida from various animal hosts - a comparison of phenotypic and genotypic methods. Trop Biomed, 28 (1): 55-63.

[7] Dabo, S.M.; Confer, A.W.; Montelongo, M. and Lu, Y.S. (1999): Characterization of rabbit Pasteurella multocida isolates by use of whole-cell, outer-membrane and polymerase chain reaction typing. Comparative Medicine, 49 (5): 551-559.

[8] Jaglic, Z.; Kucerova, Z.; Nedbalcova, K.; Hlozek, P. and Bartos, M. (2004): Identification of Pasteurella multocida serogroup $\mathrm{F}$ isolates in rabbits $\mathrm{J}$ Vet Med $\mathrm{B}$ Infect Dis Vet Public Health, 51 (10): 467469.

[9] Katsuda, K.; Hoshinoo, K.; Ueno, Y.; Kohmoto, M. and Mikami, O. (2013): Virulence genes and antimicrobial susceptibility in Pasteurella multocida isolates from calves. Vet Microbiol, 167 (3-4): 737-741.

[10] Katoch, S.; Sharma, M.; Patil, R.D.; Kumar, S. and Verma, S. (2014): In vitro and in vivo pathogenicity studies of Pasteurella multocida strains harbouring different ompA. Vet Res Commun, 38 (3): 183-191.

[11] White, D.G.; Zhao, S.; Simjee, S.; Wagner, D.D. and McDermott, P.F. (2002): Antimicrobial resistance of foodborne pathogens. Microbes Infect, 4 (4): 405-412.

[12] Ferreira, T.S.P.; Felizardo, M.R.; de Gobbi, D.D.S.; Gomes, C.R.; Filsner, P.H.D.N.; Moreno, M.; Paixao, R.; Pereira J.de.J. and Moreno, A.M (2012): Virulence genes and antimicrobial resistance profiles of Pasteurella multocida strains isolated from rabbits in Brazil. Sci. World J, 2012: ID, 685028.

[13] Varte, Z.; Dutta; T.K.; Roychoudhury, P.; Begum, J. and Chandra, R. (2014): Isolation, identification, characterization and antibiogram of Pasteurella multocida isolated from pigs in Mizoram with special reference to progressive atrophic rhinitis. Vet World, 7 (2): 95-99.

[14] Carter, G.R. and Cole, J.R. (1990): Diagnostic Procedures in Veterinary Bacteriology and Mycology, $5^{\text {th }}$ edition, Academic Press.

[15] Mutters, R.; Mannheim, W. and Bisgaard, M. (1989): Taxonomy of the group. In: Adlam, C.; Rutter, J.M., editors, pasteurella and pasteurellosis. Academic 
Press, London, United Kingdom. pp. 334.

[16] Townsend, K.M.; Frost, A.J.; Lee, C.W.; Papadimitriou, J.M. and Dawkins, H.J. (1998): Development of PCR assays for species and type-specific identification of Pasteurella multocida isolates. J Clin Microbiol,36 (4): 1096-1100.

[17] Townsend, K.M.; Boyce, J.D.; Chung, J.Y.; Frost, A.J. and Adler, B. (2001): Genetic organization of Pasteurella multocida cap Loci and development of a multiplex capsular PCR typing system. J Clin Microbiol, 39 (3): 924-929.

[18] Bauer, A.W.; Kirby, W.M.; Sherris, J.C. and Turck, M. (1966): Antibiotic susceptibility testing by standardized single disc method. Am J Clin Pathol, 45 (4): 493-496.

[19] European Committee on Antimicrobial Susceptibility Testing (EUCAST) (2017): Breakpoint tables for interpretation of MICs and zone diameters. Version 7.1. Available: http://www.eucast.org/. Accessed 10 March 2017. pp. 76-77.

[20] Tang, X.; Zhao, Z.; Hu, J.; Wu, B.; Cai, $X$. and He, Q. (2009): Isolation, antimicrobial resistance and virulence genes of Pasteurella multocida strains from swine in China. J Clin Microbiol, 47 (4): 951-958.

[21] Khalil, S.A.; Bkheet, A.A. and Gad Allah, F.A. (2017): Genetic diversity of Pasteurella multocida isolated from different animal species. Alexandria J Vet Sci, 54 (1): 173-178.

[22] Klima, C.L.; Alexander, T.W.; Hendrick, S. and McAllister, T.A. (2014): Characterization of Mannheimia haemolytica isolated from feedlot cattle that were healthy or treated for bovine respiratory disease. Can J Vet Res, 78 (1): 38-45.

[23] Asran, E.A.; Khalil, S.A. and Hegazy, A.M. (2016): Identification and molecular analysis of Pasteurella multocida isolated from rabbits. Alexandria J Vet Sci, 48 (1): 34-41.
[24] Suelam, I.I.A. and Abdel Samie, L.K. (2011): Molecular diversity of Pasteurella multocida isolated from different rabbit outbreaks at Zagazig suburbs, Egypt. Global Vet, 6: 208-212.

[25] Mazed, I.M.; Sharaf, E.M.; Zakary, E.M. and Atwa, E.I. (2013): Comparison between traditional methods and real time PCR for diagnosis of Pasteurella multocida from diseased rabbits. Benha Vet Med J, 24 (1): 12-18.

[26] Verma, S.; Sharma, M.; Katoch, S.; Verma, L.; Kumar, S.; Dogra, V.; Chahota, R.; Dhar, P. and Singh, G. (2013): Profiling of virulence associated genes of Pasteurella multocida isolated from cattle. Vet Res Commun, 37 (1): 83-89.

[27] Kour, A.; Verma, S.; Singh, G.; Katoch, S.; Sharma, M. and Singh, G. (2016): Characterization and different antigenic preparations of $P$. multocida along with their quantitative and qualitative analysis. J Anim Res, 6 (4): 733-741.

[28] Rimler, R.B. and Rhoades, K.R. (1989): Pasteurella multocida. In: Pasteurella and pasteurellosis. Adlam, C.; Rutter, J.M. editors. Academic Press, New York, NY. pp. 31-73.

[29] Krishna, S.V.; Agarwal, R.K. and Nagaleekar, V.K. (2017): Capsular typing and antibiogram study of Pasteurella multocida isolates of rabbit origin. Int J Curr Microbiol App Sci, 6 (12): 4352-4357.

[30] Balakrishnan, G.; Roy, P.; Nagarajan, K.; Selvaraj, J. and Manohar, B.M. (2012): Isolation, identification and antibiogram of Pasteurella multocida isolates of rabbits suffering from pasteurellosis. Int J Agro Vet Med Sci, 6: 58-61.

[31] El-sayed, M.E.; El-Mowalid, G.A.; Aisha, R. Ali; Marwa, I. Arnaout and Marwa, I. Abd El-Hamid (2018): Isolation, identification and antimicrobial susceptibility patterns of Pasteurella multocida isolated from diseased rabbits. Suez Canal Vet Med J, XXIII: 13-26 
[32] Cucco, L.; Massacci, F.R.; Sebastiani, C.; Mangili, P.; Bano, L.; Cocchi, M.; Luppi, A.; Ortenzi, R.; Pezzotti, G. and Magistrali, C.F. (2017): Molecular characterization and antimicrobial susceptibility of Pasteurella multocida strains isolated from hosts affected by various diseases in Italy. Vet Ital, 53 (1): 21-27.

[33] Sarangi, L. N.; Priyadarshini, A.; Kumar, S.; Thomas, P.; Gupta, S.K.; Nagaleekar, V.K. and Pal Singh, V. (2014): Virulence genotyping of Pasteurella multocida isolated from multiple hosts from India. Sci. World J, 2014: ID, 814109.

[34] Pullinger, G.D.; Bevir, T. and Lax, A.J. (2004): The Pasteurella multocida toxin is encoded within a lysogenic bacteriophage. Mol Microbiol, 51 (1): 255-269.

[35] Jaglic, Z.; Kucerova, Z.; Nedbalcova, K.; Pavlik, I.; Alexa, P. and Bartos, M. (2005): Characterization and comparison of Pasteurella multocida isolated from different species in the Czech Republic: capsular PCR typing, ribotyping and dermonecrotoxin production. Vet Med Czesh, 50 (8): 345-354.

[36] Cummings, K.J.; Perkins, G. A.; Khatibzadeh, S.M.; Warnick, L.D. and Altier, C. (2013): Antimicrobial resistance trends among Salmonella isolates obtained from dairy cattle in the northeastern United States, 2004-2011. Foodborne Pathog Dis, 10 (4): 353-361.

[37] Wang, Z.; Kong, L.C.; Jia, B.Y.; Liu, S.M.; Jiang, X.Y. and Ma, H.X. (2017):
Aminoglycoside susceptibility of Pasteurella multocida isolates from bovine respiratory infections in China and mutations in ribosomal protein S5 associated with high-level induced spectinomycin resistance. J Vet Med Sci, 79 (10): 1678-1681.

[38] San Millan, A.; Escudero, J.A.; Gutierrez, B.; Hidalgo, L.; Garcia, N.; Llagostera, M.; Dominguez, L. and Gonzalez-Zorn, B. (2009): Multiresistance in Pasteurella multocida is mediated by coexistence of small plasmids. Antimicrob Agents Chemother, 53 (8): 3399-3404.

[39] Hansen, L.M.; Blanchard, P.C. and Hirsh, D.C. (1996): Distribution of $\operatorname{tet}(\mathrm{H})$ among pasteurella isolates from the United States and Canada. Antimicrob Agents Chemother, 40 (6): 1558-1560.

[40] Woodford, N.; Carattoli, A.; Karisik , E.; Underwood, A.; Ellington, M.J. and Livermore, D.M. (2009): Complete nucleotide sequences of plasmids pEK204, pEK499 and pEK516, encoding CTX-M enzymes in three major Escherichia coli lineages from the United Kingdom, all belonging to the international O25:H4-ST131 clone. Antimicrob Agents Chemother, 53 (10): 4472- 4482.

[41] Srisanga, S.; Angkititraku, S.; Sringam, P.; LeHo, P.T.; TVo, A.T. and Chuanchuen, R. (2017): Phenotypic and genotypic antimicrobial resistance and virulence genes of Salmonella enterica isolated from pet dogs and cats. J Vet Sci, 18 (3): 273-281. 


\section{الملخص العربي}

$$
\begin{aligned}
& \text { مصاحبة جينات ضراوة ومقاومة المضادات الحيوية فى الباستريلا مالتوسيدا المعزولة من الأرانب المريضة }
\end{aligned}
$$

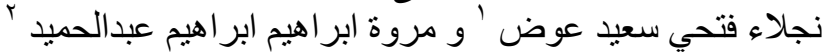

$$
\begin{aligned}
& \text { ' قسم طب الطيور و الأرانب، كلية الطب التيطري، جامعة الزقازيق، الزقازيق، الزئ، الثرقية، }
\end{aligned}
$$

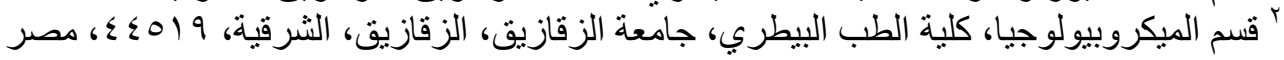

تعتبر الباستريلا مالتوسيدا من العو امل البكتيرية السائدة المسببة لأعراض تنفسية فى الأر انب مما يؤدى إلى خسائر اقتصادية

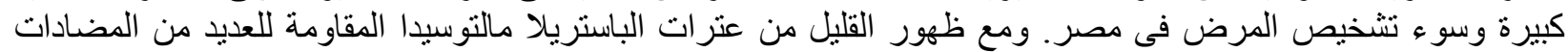

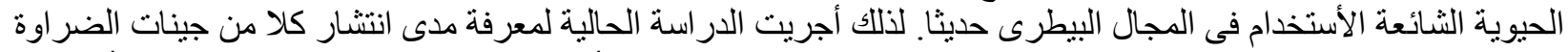

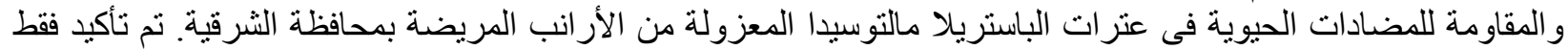

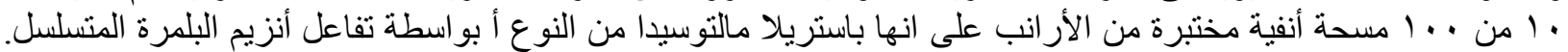

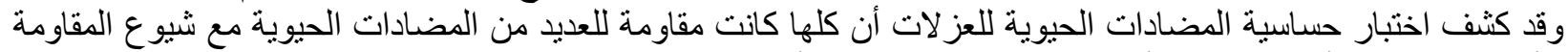

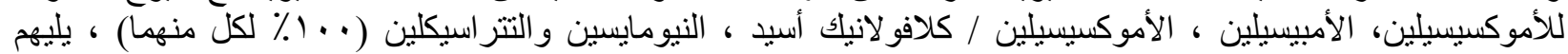

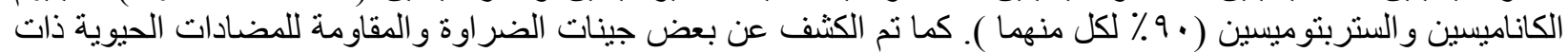

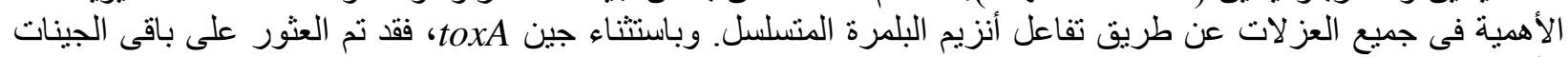

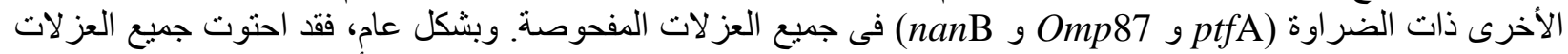

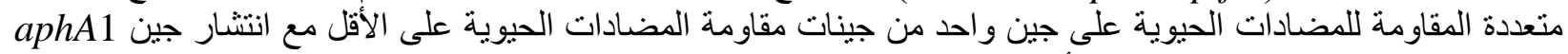

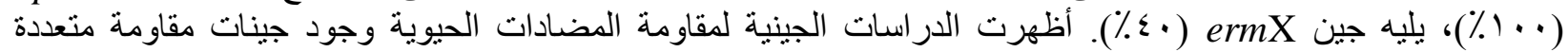

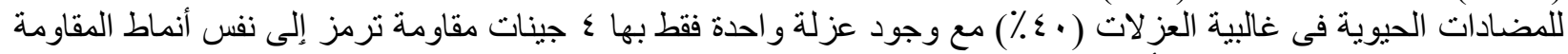

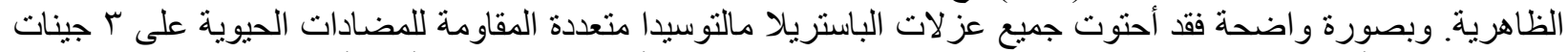

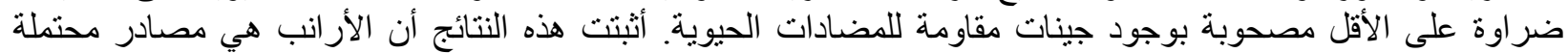

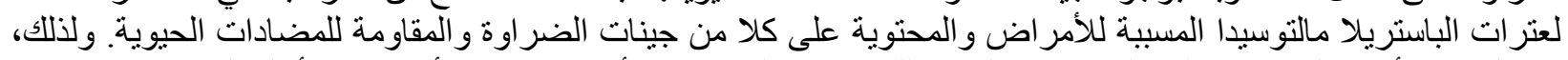

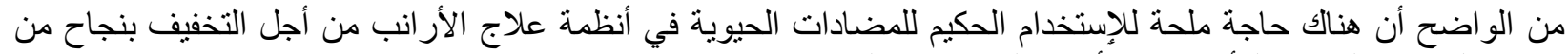

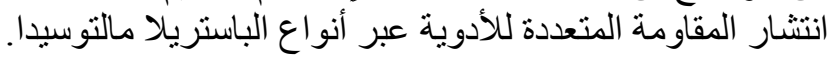

